Célia Landmann Szwarcwald 1 Francisco Inácio Bastos 1 Christovam Barcellos 1 Maria Angela Pires Esteves 1 Euclides Ayres de Castilho 2

\section{Dinâmica da epidemia de AIDS no Município do Rio de Janeiro, no período de 1988-1996: uma aplicação de análise estatística espaço-temporal}

\author{
Spatial-temporal modeling: dynamics of the AIDS \\ epidemic in the municipality of Rio de Janeiro, \\ Brazil, 1988-1996
}

1 Departamento de Informações em Saúde, Centro de Informação Científica e Tecnológica, Fundação Oswaldo Cruz. Av. Brasil 4365, Rio de Janeiro, $R J$ 21045-900, Brasil. celials@fiocruz.br 2 Coordenação Nacional de DST e AIDS, Secretaria de Politicas de Saúde, Ministério da Saúde. Esplanada dos Ministérios, Bloco G, Edifício Sede, Sobreloja, Brasília, DF 70058-900, Brasil.

\begin{abstract}
This study uses a spatial-temporal model to analyze the spatial spread of the AIDS epidemic (adult cases) in the municipality of Rio de Janeiro, Brazil, during three periods: 19881990, 1991-1993, and 1994-1996. City districts were used as the geographic units of analysis. A spatial analysis was also performed for pediatric AIDS cases due to vertical HIV transmission, according to period of birth, 1985-90 and 1991-96. For total adult AIDS cases, the initial period was characterized by a polygonal cluster located around the harbor area, which expanded from west to east. Among homosexual cases, in situ growth predominated, and a decrease in the intensity of the diffusion process was observed from the second to the final period. Among heterosexual cases, the epidemic displayed a relevant geographic spread, mainly from 1988-1990 to 1991 1993. Among female cases in the final time period, a cluster of high incidence rates was found towards the northwest, including very poor areas. Among pediatric cases in 1991-1996, a significant correlation was found between AIDS incidence rates and poverty levels in the respective municipal districts. The results suggest that a more complete understanding of AIDS spatialtemporal dynamics can make a major contribution to preventive measures.
\end{abstract}

Key words Spatial Analysis; Temporal Analysis; Acquired Immunodeficiency Syndrome

Resumo Neste estudo, aplicou-se um modelo espaço-temporal para examinar a disseminação espacial da epidemia de AIDS entre os casos adultos do Município do Rio de Janeiro em três períodos: 1988-1990, 1991-1993 e 1994-1996. As regiões administrativas foram as unidades geográficas de estudo. Posteriormente, realizou-se análise espacial dos casos pediátricos por transmissão vertical do HIV, por período de nascimento, 1985-1990 e 1991-1996. Para a totalidade dos casos adultos, o período inicial é caracterizado por um conglomerado poligonal em torno da Zona Portuária, que se expande na direção oeste-leste. Entre os casos homossexuais, o crescimento in situ predominou, notando-se arrefecimento da disseminação espacial nos últimos anos. Entre os casos heterossexuais, a epidemia demonstrou expansão geográfica expressiva, sobretudo de 1988-1990 a 1991-1993. Entre os casos do sexo feminino, no último período, houve a formação de um conglomerado de taxas elevadas na direção noroeste, que compreende áreas muito pobres. Entre 1991 e 1996, observou-se correlação significativa das taxas de incidência de AIDS perinatal com o índice de concentração de pobreza. Os resultados sugerem que o entendimento da dinâmica espaço-temporal da epidemia pode subsidiar, de forma relevante, as ações preventivas. Palavras-chave Análise Espacial; Análise Temporal; Síndrome de Imunideficiência Adquirida 


\section{Introdução}

A análise estatística espacial tem se tornado uma metodologia de importância crescente entre os campos de pesquisa que lidam com informações geograficamente referenciadas. Entre esses, destacam-se as aplicações na pesquisa epidemiológica (Kheifets, 1993). Incorporando o conhecimento sobre processos estocásticos espaciais e a dependência das observações no espaço (Cressie, 1993), o uso dessa metodologia tem fornecido contribuições relevantes aos estudos de distribuição espacial da ocorrência de doenças (Hills \& Alexander, 1989; Marshall, 1991).

Particularmente, os procedimentos de análise espaço-temporal, permitindo não só estimar associações espaciais mas também a interação espaço-temporal, têm atraído o interesse dos epidemiologistas. Esses modelos podem contribuir para a compreensão dos processos de disseminação espacial das doenças ao longo do tempo, possibilitando a detecção de potenciais fatores de risco (Jacquez, 1996; Kulldorf \& Nagarwalla, 1995; Mayer, 1983).

A investigação da existência de conglomerados espaço-temporais em uma série de observações georeferenciadas foi abordada, primeiramente, por Knox (1964), que propôs um índice de interação espaço-temporal baseado no número de pares de observações em intervalos fixos de distâncias espaciais e temporais. O coeficiente de Knox foi generalizado por Mantel (1967), utilizando como índice de proximidade espaço-temporal uma medida de covariância, calculada como o produto dos inversos das distâncias espacial e temporal. Desde então, para a análise espaço-temoral de padrões de pontos, vários outros procedimentos foram propostos (Besag \& Newell, 1991; Tango, 1995).

No que diz respeito à análise espacial de dados observados em áreas geográficas (lattice data), o primeiro modelo foi desenvolvido por Cliff \& Ord (1973), e aplicado por Hagget (1976), para analisar o padrão de disseminação de sarampo. Anos mais tarde, generalizando o coeficiente de autocorrelação de Moran (1950), Cliff \& Ord (1981) propuseram uma medida para testar a presença de conglomerados espaciais, que tem sido amplamente utilizada nos estudos epidemiológicos, recorrendo-se a variadas aproximações desse índice (Oden, 1995; Waldhor, 1996).

Em outro exemplo de possibilidade de uso dessa medida, Szwarcwald \& Bastos (1998) demonstraram que o coeficiente generalizado de Moran (Cliff \& Ord, 1981), pode também ser usado para estimar a interação espaço-temporal por meio da definição de adequadas matrizes de ponderações espaciais.

Entretanto, nos estudos do processo de disseminação de uma doença infecciosa, o uso de uma medida de autocorrelação espaço-temporal, que mede a covariância da observação em uma determinada área e em um certo tempo, com observações em áreas vizinhas no tempo anterior, traz a desvantagem de não relacionar observações consecutivas à tendência de conglomeração das anteriores (Lawson \& Viel, 1995). No caso de uma doença transmissível, como por exemplo, a AIDS, o número de pessoas afetadas em uma unidade de tempo depende do número de indivíduos já infectados (Halloran \& Struchiner, 1991). O interesse maior recai em mensurar a interação espaço-temporal, somente depois de ter ajustado pela tendência no tempo.

O ajuste simultâneo dos efeitos espaçotemporais e efeitos temporais foi proposto por Cliff \& Ord (1981), ao reexaminar os dados da epidemia de cólera em Londres, no ano de 1849, através de uma nova aproximação metodológica. Os autores evidenciaram a importância de distinguir os efeitos de crescimento in si$t u$ (tendência local de crescimento), dos efeitos de difusão espacial, que representam o deslocamento da doença para outras áreas.

\section{O modelo espaço-temporal}

Analisando a disseminação espacial de cólera pelos bairros de Londres, utilizando os dados da epidemia que ocorreu naquela cidade, em 1849, Cliff \& Ord (1981) propuseram a utilização do modelo espaço-temporal (1), descrito a seguir:

$$
y_{i t}=\phi_{0}+\phi_{t} y_{i, t-1}+\phi_{s t} \sum_{j \neq i} w_{i j} y_{j, t-1}+e_{i, t}
$$

onde $w_{i j}$ são as ponderações espaciais definidas para cada par de áreas geográficas $(i, j) i, j$ variando de la $n$, onde $n$ é o número de áreas geográficas; $y_{i t}$ são as taxas de incidência observadas na área $i$ no tempo $t$; e $e_{i t}$ são os resíduos do modelo.

É importante notar que este modelo é apropriado para aplicação em dados de áreas (lattice data) onde as ponderações espaciais podem ser definidas com base em diferentes critérios de vizinhança, como o da contigüidade ou distância entre áreas geográficas.

O objetivo da aplicação deste modelo às taxas de incidência de uma certa doença, recai em distinguir a importância relativa de cada 
variável na explicação da resposta, buscandose distinguir o efeito do crescimento in situ, isto é, crescimento localizado apenas na áreas que já detinham o maior número de casos no tempo anterior, do efeito de difusão espacial, medido pela contribuição da interação espaço-temporal, que reflete a expansão da doença para áreas vizinhas. Se o crescimento in situ for mais importante, espera-se que o coeficiente $\phi_{t}$ demonstre maior significância estatística do que o coeficiente $\phi_{s t}$, e vice-versa, se o parâmetro correspondente à interação espaço-temporal mostrar efeito mais significativo, a disseminação espacial é o processo predominante.

Para a análise espaço-temporal da epidemia de cólera em Londres, Cliff \& Ord (1981) utilizaram um procedimento stepwise de regressão, estimando os parâmetros do modelo em cada passo pelo método dos "mínimos quadrados" (baseado em minimizar a soma dos quadrados dos erros) já que, como demonstrado por Besag (1977), os estimadores por mínimos quadrados são consistentes no sentido estatístico (estimador consistente é um estimador não tendencioso, cujo desvio em relação ao parâmetro que está sendo estimado tende a zero, à medida que cresce o número de observações). Apesar de fugir ao escopo deste trabalho a demonstração de consistência deste tipo de estimação, delinea-se, a seguir, a prova utilizada por Besag (1977).

Inicialmente, pode-se demonstrar que o modelo (1) pode ser também escrito sob a forma condicional, onde a esperança da observação em um determinado tempo e área é uma função linear das observações na mesma área e em áreas vizinhas no tempo anterior.

Sob o pressuposto de que as distribuições condicionais são normais, pode-se demonstrar que o vetor constituído das observações em todas as localidades, medidas nos dois tempos consecutivos, tem distribuição normal multivariada, cuja matriz de variâncias-covariâncias obedece às condições necessárias para que a estimação por mínimos quadrados forneça estimadores consistentes para os parâmetros do modelo (1).

Sendo assim, o modelo espaço-temporal pode ser aplicado de maneira tradicional, estimando-se os parâmetros por mínimos quadrados, ou seja, pelos procedimentos usuais de regressão múltipla.

\section{Análise da disseminação espacial da AIDS no Município do Rio de Janeiro}

Desde o trabalho pioneiro de Klovdahl (1985), escrito num momento em que a própria etiologia da síndrome de imunodeficiência adquirida era ainda objeto de investigações preliminares e debates, a difusão da epidemia de HIV/ AIDS se mostrou claramente direcional, ou seja, a epidemia reflete no seu processo de difusão, ao longo das redes sociais e do espaço, as características de uma infecção transmitida exclusivamente pelo contato íntimo entre as pessoas (mediado pelo sangue, sêmen e líquido vaginal) e, portanto, seletivos (Morris, 1991).

Enquanto os trabalhos epidemiológicos iniciais enfatizaram, exclusivamente, os fatores de risco para a infecção pelo HIV no plano dos indivíduos, os trabalhos posteriores vêm incorporando aspectos referentes à natureza das parcerias (sexuais ou de uso compartilhado de seringas, agulhas ou outros objetos perfurocortantes, assim como variáveis referentes à dimensão cultural e à estrutura social e econômica do local onde ocorre a difusão da infecção pelo HIV).

Esta ampliação do marco conceitual é basicamente tributária da confluência da introdução e desenvolvimento do conceito de vulnerabilidade (Mann et al., 1992) e do desenvolvimento de técnicas de análise epidemiológica, estatística e matemática capazes de compreender o processo de difusão do HIV/AIDS em uma dimensão, simultaneamente, temporal e espacial (Lam et al., 1996; Löytönen, 1994), levando igualmente em conta as particularidades da epidemiologia das doenças infecciosas (Anderson, 1996; Brookmeyer, 1996).

As dimensões social e geográfica da vulnerabilidade para a infecção pelo HIV têm sido exploradas sob diversos pontos de vista, tais como: a relevante difusão do HIV/AIDS nas comunidades mais pobres e carentes de recursos e infra-estrutura de serviços de atenção à saúde (Greenland et al., 1996; Wallace \& Wallace, 1995); o papel central das desigualdades de gênero na determinação dos modos de "pareamento" e interação entre os gêneros; e a especial vulnerabilidade das mulheres frente ao HIV/AIDS (Zierler \& Krieger, 1997).

No Brasil, os estudos ecológicos acerca da dinâmica da epidemia pelo HIV/AIDS são ainda pouco freqüentes (Barcellos \& Bastos, 1996; Bastos \& Barcellos, 1995; Grangeiro, 1994; Szwarcwald et al., 1997, 1998). Particularmente, no que diz respeito à disseminação espacial da epidemia no interior das metrópoles brasileiras, tais estudos são essenciais tanto para a 
apreciação das variações intra-urbanas dos processos de difusão espaço-temporal como para a proposição de estratégias preventivas sensíveis às disparidades sociais e culturais presentes nas grandes cidades.

O objetivo do presente trabalho é aplicar o modelo espaço-temporal de Cliff \& Ord (1981) para estudar o processo de disseminação espacial da epidemia de AIDS no Município do Rio de Janeiro, no período de 1988-1996, procurando-se caracterizar os processos de difusão espacial dos casos adultos por categoria de exposição ao vírus da imunodeficiência humana (HIV), ao longo do tempo.

Os efeitos de interação espaço-temporal, que expressam a disseminação espacial ao longo do tempo, ajustados pelos efeitos de crescimento in situ, foram estimados pela aplicação do modelo (1) às taxas de incidência de AIDS, tendo como unidades geográficas de análise as regiões administrativas em que o município estava subdividido no início do período estudado.

Posteriormente, realizou-se análise estatística espacial dos casos pediátricos decorrentes da transmissão vertical do HIV, estratificandose por período de nascimento da criança. Reflexo da infecção materna por HIV, a investigação das crianças infectadas por transmissão vertical, segundo o ano de nascimento, teve o objetivo de mostrar um quadro mais recente da infecção pelo vírus entre as mulheres.

\section{Metodologia}

Como fonte de informações para os casos de AIDS de indivíduos residentes no Município do Rio de Janeiro, foi utilizado o Sistema de Notificação da Secretaria Municipal de Saúde do Rio de Janeiro, que contém além de todas as informações do Sistema de Notificação da Coordenação Nacional de DST e AIDS do Ministério da Saúde, o bairro e a Região Administrativa (RA) de residência dos casos. Foram considerados, inicialmente, todos os homens e mulheres com idade maior ou igual a 15 anos, com ano de diagnóstico no período de 1988 e 1996. Em uma análise posterior, foram consideradas todas as crianças, com menos de 13 anos de idade, com relação à transmissão vertical, e com ano de nascimento entre 1986 e 1995.

Como unidades geográficas de análise, foram utilizadas as 26 regiões administrativas que compunham o Município do Rio de Janeiro no início do período estudado, conforme ilustrado na Figura 1.

Em relação à análise dos adultos, os casos de AIDS foram agrupados em três períodos de tempo: 1988-1990, 1991-1993 e 1994-1996, no sentido de obter maior fidedignidade das taxas de incidência da AIDS por RA, uma vez que o número anual de casos de AIDS é reduzido, com possíveis oscilações das taxas anuais de incidência. Os períodos aqui considerados levam em conta a curva de crescimento da epidemia no Município do Rio de Janeiro, que se acentua no início dos anos 90, sendo que o último ano incluído no estudo (1996) procura evitar possível viés decorrente do atraso de notificação (Barbosa \& Struchiner, 1997).

As populações que constituíram os denominadores das taxas médias trienais foram obtidas por projeção geométrica das informações censitárias de 1991 (IBGE, 1994) e 1996 (IBGE, 1998).

A transformação da raiz quadrada foi utilizada como controladora da variância das taxas de incidência de AIDS, calculadas por RA, que apresentavam grandes desvios em relação à distribuição normal. Para analisar a disseminação espacial da AIDS no Município do Rio de Janeiro foi utilizado o modelo espaço-temporal (1) tendo como variáveis-resposta as taxas transformadas, estimando-se os efeitos de crescimento in situ e os efeitos de interação espaço-temporal em dois momentos, do período 1 (1988-1990) para o período 2 (1991-1993) e do período 2 (1991-1993) para o período 3 (19941996). A análise espaço-temporal foi realizada para quatro agrupamentos dos casos notificados de AIDS, a saber: a) a totalidade dos casos de AIDS; b) todos os casos por transmissão heterossexual, incluindo homens e mulheres; c) todos os casos do sexo masculino por transmissão homossexual; d) todas as mulheres adultas.

Para a visualização da difusão espacial das taxas de incidência de AIDS por agrupamento considerado no estudo, ao longo do tempo, foram elaborados mapas relativos aos três períodos, seguindo a mesma escala de intervalos, por meio do software MapInfo (1994). A divisão das faixas temáticas foi baseada nas taxas do período 1991-1993, representando pela cor cinza escuro as RAs com as sete taxas mais elevadas, pelo cinza claro aquelas com as sete menores taxas e as 12 restantes pelo cinza médio.

Tendo em vista que o modelo de análise espaço-temporal relaciona a observação em um determinado tempo com o pool de casos passíveis de transmitir a infecção, na própria área, assim como nas áreas vizinhas no tempo anterior, no caso do estudo entre as mulheres, o modelo (1) foi utilizado de forma algo distinta. A variável resposta referiu-se à taxa de incidência entre as mulheres, enquanto as variáveis independentes às taxas de incidência entre os ca- 


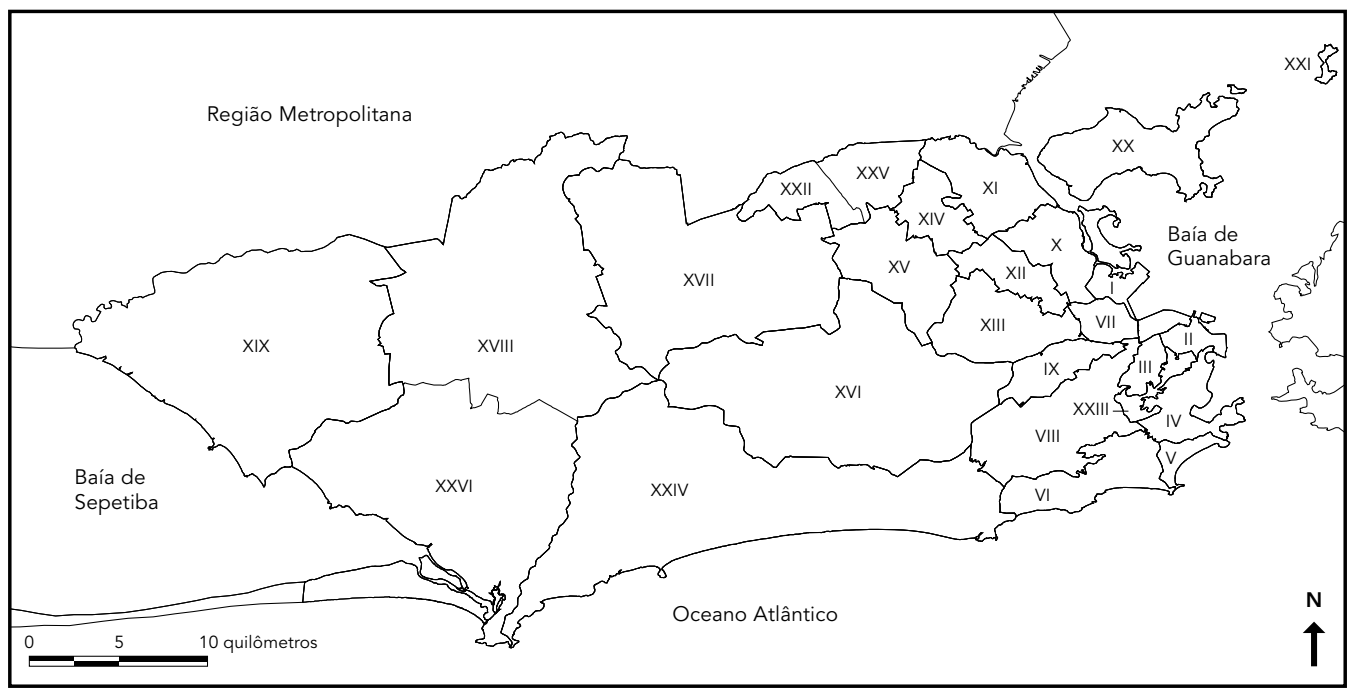

I - Portuária II - Centro

III - Rio Comprido

IV - Botafogo

V-Copacaban

$\mathrm{VI}$ - Lagoa

VII - São Cristóvão

VIII - Tijuca

IX - Vila Isabel

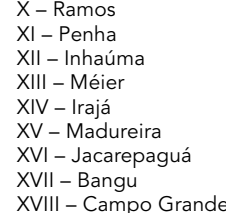
$X X$ - Ilha do Governador $X X I$ - Illha de Paquetá XXII - Anchieta XXIII - Santa Tereza XXIV - Barra da Tijuca $X X V$ - Pavuna XXVI - Guaratiba

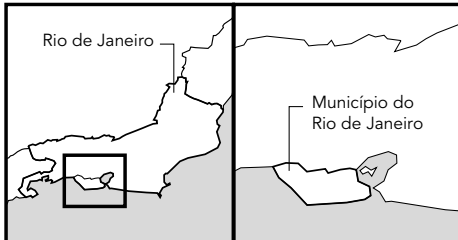

Fonte: SIG-FIOCRUZ.

sos heterossexuais masculinos, observadas na própria RA e nas RAs vizinhas no tempo anterior.

A definição das ponderações espaciais $\left(w_{i j}\right)$ obedeceu a dois critérios. O primeiro envolveu apenas a contigüidade entre as RAs, definindose pesos binários iguais a um no caso de RAs vizinhas, e iguais a zero no caso oposto. O segundo envolveu também a direção do vetor de ligação entre os centróides das RAs, sendo consideradas quatro direções distintas: 45 graus ( $\pi / 8 \mathrm{rd}, 3 \pi / 8 \mathrm{rd}$ ); 90 graus $(3 \pi / 8 \mathrm{rd}, 5 \pi / 8 \mathrm{rd}$ ); 135 graus $(5 \pi / 8 \mathrm{rd}, 7 \pi / 8 \mathrm{rd}$ ); 180 graus $(7 \pi / 8 \mathrm{rd}$, $9 \pi / 8 \mathrm{rd}]$. Em todas as vezes, para cada área $i$, as ponderações $\left(w_{i j}\right)$ foram escalonadas para ter soma igual a um.

Por intermédio de procedimentos stepwise de regressão múltipla, com nível de significância de inclusão de uma variável de $10 \%$ e de exclusão de $15 \%$, testou-se qual o efeito mais importante, o temporal, correspondente ao crescimento in situ, ou o de interação espaço-temporal, tanto do período 1 (1988-1990) para o 2
(1991-1993), como do período 2 para o 3 (19941996). Para analisar a direcionalidade e testar a anisotropia do processo de disseminação espacial, as variáveis correspondentes A cada um dos efeitos direcionais foram testadas para inclusão no modelo, conjuntamente com a variável referente ao efeito temporal. Optou-se por utilizar os níveis de $10 \%$ (inclusão) e 15\% (exclusão) em virtude do número reduzido de pares de RAs em determinadas direções.

A construção das variáveis utilizadas no modelo espaço-temporal (1) foi elaborada através de programa em linguagem $\mathrm{C}$, desenvolvido por um dos autores deste artigo (C.L.S.). Para a estimação dos parâmetros do modelo por mínimos quadrados, utilizou-se o software SPSS (1995).

Em etapa posterior da análise, foram examinadas todas as crianças, com menos de 13 anos de idade, classificadas na categoria de exposição "transmissão vertical” (doravante também denominada "AIDS perinatal”), nascidas entre 1985 e 1996, por RA de residência. Saben- 
do-se que o percentil 75 da diferença entre o ano de diagnóstico e o ano de nascimento é de três anos, o último ano de nascimento a ser considerado na análise foi o de 1996.

Os casos por transmissão vertical foram agrupados em dois períodos, de acordo com o ano de nascimento da criança: 1985-1990 e 1991-1996. Para o cálculo das taxas de incidência, foram utilizados como denominadores os números de nascidos vivos, em 1995, por RA de residência da mãe, tendo como fonte de informações o Sistema de Nascimentos (SINASC) do Município do Rio de Janeiro. Devido à falta de informações sobre o número de nascidos vivos por RA anteriores à implantação do SINASC no município, o mesmo denominador foi usado para os dois períodos de tempo.

Com o objetivo de investigar a hipótese de existência de conglomerados espaciais em cada período de tempo, foram feitas duas análises espaciais independentes, tomando-se como variável de investigação a raiz quadrada da taxa de incidência de AIDS perinatal. O coeficiente padronizado de autocorrelação de Moran foi a estatística utilizada para testar a hipótese de distribuição espacial aleatória, sendo que os momentos do coeficiente foram estimados sob o pressuposto de normalidade das taxas de incidência (Cliff \& Ord, 1981). A definição de vizinhança obedeceu aos mesmos dois critérios utilizados para os adultos. Os testes foram feitos por meio de programa desenvolvido em linguagem $\mathrm{C}$ especificamente para este fim.

Adicionalmente, para melhor interpretação dos resultados da análise espacial, as taxas de incidência de AIDS perinatal foram correlacionadas a dois indicadores que expressam o padrão sócio-econômico da RA, "proporção de chefes de domicílio que têm renda mensal menor que um salário mínimo" e "proporção de mulheres de 15-49 anos analfabetas", construídos a partir das informações do Censo Demográfico de 1991 (IBGE, 1994).

\section{Resultados}

A disseminação espacial da epidemia de AIDS, no Município do Rio de Janeiro, ao longo do período 1988-1996, pode ser apreciada pelos mapas apresentados na Figura 2. As medianas das taxas de incidência nos três períodos foram de, respectivamente, 28, 39 e 42 por 100.000 habitantes. No primeiro período as taxas variaram de zero a 148, no segundo de 10 a 201 e no terceiro de 7 a 176, sendo que os valores máximos foram sempre apresentados pela RA Centro.
As características sócio-econômicas e demográficas das regiões administrativas do Rio de Janeiro foram descritas com detalhe em trabalho anterior (Szwarcwald et al., 1999a).

Verifica-se uma concentração inicial de taxas elevadas em torno da região Centro/Portuária, onde ocorreram os primeiros casos, e no litoral, sendo que o Centro, a Região Portuária, Copacabana, Rio Comprido, Santa Teresa e Botafogo são as RAs que mais se destacam. Ao longo do tempo, há um nítido processo de expansão da epidemia, do litoral para o interior do município.

Correspondentemente, o modelo espaçotemporal utilizado demonstra a predominância do crescimento in situ (Tabela 1). Os efeitos temporais são estatisticamente significativos, tanto do primeiro para o segundo período de tempo, como do segundo para o terceiro. O único efeito espaço-temporal significativamente diferente de zero ocorre para a direção de 180 graus (horizontal) de 1988-1990 para 1991-1993, que aponta para a grande difusão da epidemia que tem lugar, justamente, após os anos 90, e para o processo de expansão visualizado no mapa.

A apreciação das distribuições espaciais das taxas de incidência relativas à categoria de exposição dos homossexuais (Figura 3) mostra que a evolução da epidemia nesta população, do primeiro para o segundo período de tempo, é bastante semelhante à da totalidade dos casos. Esses resultados indicam que a disseminação geográfica da epidemia de AIDS, até 1993, no Município do Rio de Janeiro, retratava, predominantemente, o processo espacial evolutivo que ocorreu entre os casos homossexuais masculinos, amplamente majoritários (37\% dos casos acumulados até o ano de 1993). Porém, entre estes últimos, nota-se uma retração da disseminação da epidemia nos anos mais recentes, o que não ocorre para a totalidade dos casos. As RAs que apresentavam as quatro maiores taxas de incidência entre os homossexuais masculinos no período de 1991-1993 (Centro, Copacabana, Botafogo e Santa Teresa) mostraram redução expressiva na magnitude das taxas no período 1994-1996.

A análise estatística elaborada para a categoria de casos homossexuais corrobora os achados geográficos, mostrando de forma ainda mais acentuada a ausência de difusão espacial e a predominância do crescimento in situ. A estimação dos parâmetros demonstra efeitos temporais com significância estatística $(p<0,0001)$ nos dois momentos estudados, expressando o crescimento concentrado nas áreas com taxas elevadas desde o início da epidemia. Já no que se refere aos efeitos de interação espaço-temporal, apenas o corresponde à direção $\pi$, do pri- 


\section{Figura 2}

Distribuição espacial das taxas de incidência de AIDS (por 100.000 habitantes) por período de tempo. Município do Rio de Janeiro, 1988-1996.

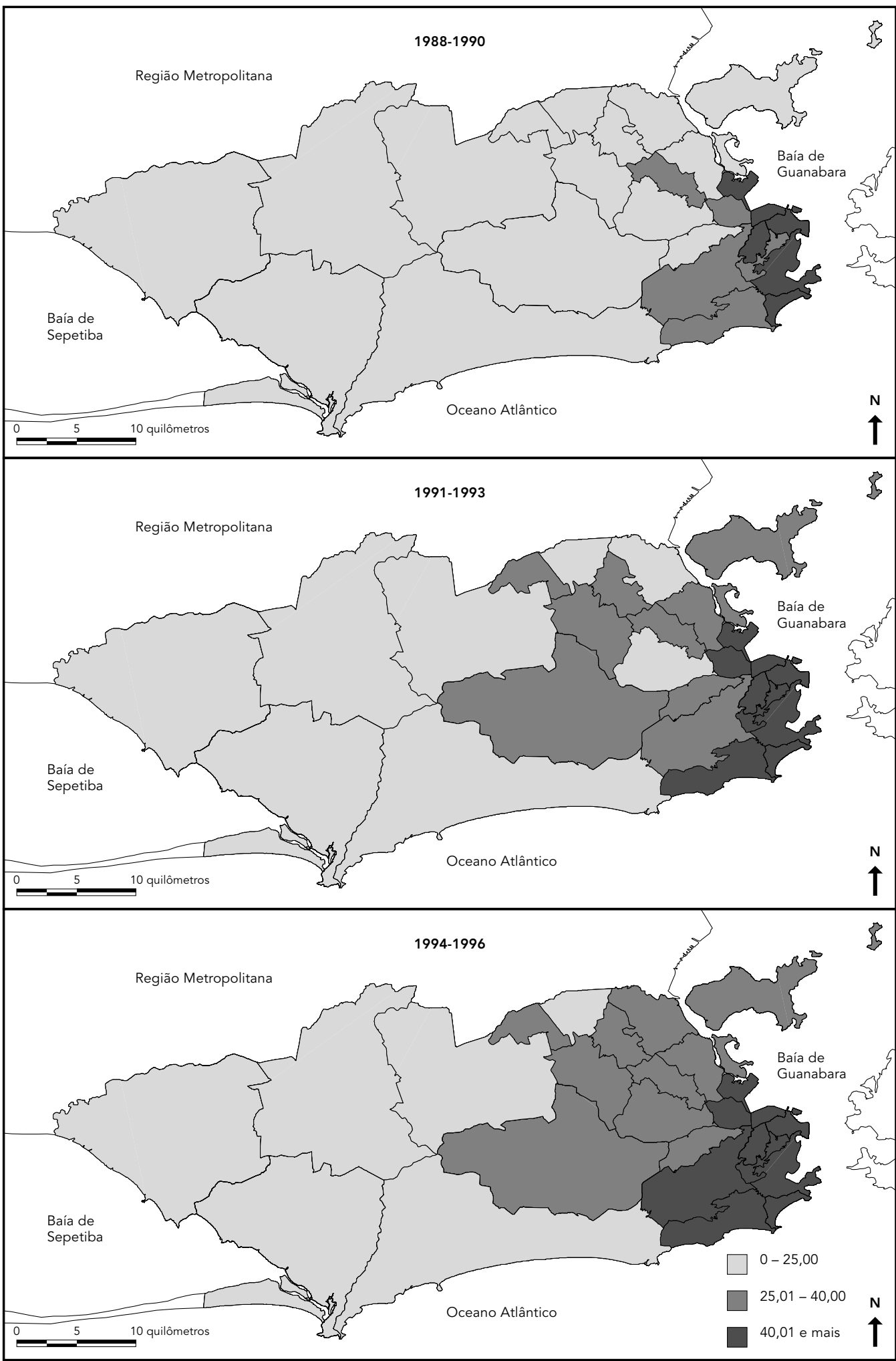


Resultados do procedimento stepwise para a totalidade dos casos.

\begin{tabular}{|c|c|c|c|c|}
\hline \multirow[t]{2}{*}{ Variáveis } & \multicolumn{2}{|c|}{ Período 1 para o Período 2} & \multicolumn{2}{|c|}{ Período 2 para o Período 3} \\
\hline & Parâmetro & p-valor & Parâmetro & p-valor \\
\hline Constante & 1,005 & 0,003 & 1,046 & 0,002 \\
\hline Vizinho temporal & 0,992 & 0,000 & 0,873 & 0,000 \\
\hline Vizinho espaço-temporal & - & NS & - & NS \\
\hline Constante & 0,216 & 0,563 & 1,112 & 0,008 \\
\hline Vizinho temporal & 1,109 & 0,000 & 0,868 & 0,000 \\
\hline Vizinho espaço-temporal na direção de $45^{\circ}$ & - & NS & - & NS \\
\hline Constante & 1,566 & 0,003 & 0,807 & 0,095 \\
\hline Vizinho temporal & 0,869 & 0,000 & 0,906 & 0,000 \\
\hline Vizinho espaço-temporal na direção de 90॰ & - & NS & - & NS \\
\hline Constante & 0,777 & 0,029 & 0,883 & 0,017 \\
\hline Vizinho temporal & 1,013 & 0,000 & 0,905 & 0,000 \\
\hline Vizinho espaço-temporal na direção de $135^{\circ}$ & - & NS & - & NS \\
\hline Constante & 0,425 & 0,384 & 1,037 & 0,033 \\
\hline Vizinho temporal & 0,807 & 0,000 & 0,860 & 0,000 \\
\hline Vizinho espaço-temporal na direção de $180^{\circ}$ & 0,329 & 0,008 & - & NS \\
\hline
\end{tabular}

NS = não significante.

meiro para o segundo período de tempo, é significativamente diferente de zero $(\mathrm{p}=0,031)$.

Em contraste, se a epidemia entre os casos homossexuais masculinos pode ser descrita, basicamente, por um processo de crescimento in situ, a epidemia entre as mulheres e os homens infectados por transmissão heterossexual demonstra claros sinais de expansão geográfica ao longo do tempo (Figura 4). O mapa temático referente ao período 1988-1990 mostra que somente as RAs de Santa Teresa e Centro tinham taxas de incidência maiores do que 3,4 por 100.000 habitantes. Já no período de 1994-1996, todas as RAs possuíam taxas mais elevadas do que esse valor, a exceção cabendo apenas a Guaratiba e Paquetá.

O modelo estatístico aponta para a grande difusão espacial, do período de 1988-1990 para o período 1991-1993, entre os casos heterossexuais (Tabela 3). Há nítidas evidências de expansão geográfica de uma área para as áreas contíguas, independentemente da direção do eixo de ligação entre as RAs, sendo o efeito espaço-temporal mais significativo $(\mathrm{p}=0,002)$ do que o efeito temporal $(p=0,025)$. Embora haja desaceleração da disseminação geográfica do período intermediário para o terceiro, com a ocorrência mais expressiva do crescimento in $s i t u$, o efeito espaço-temporal na direção 90 graus é relevante, apontando para uma difusão da epidemia na direção norte, no sentido da área metropolitana do estado.

Acompanhando a expansão da epidemia entre os heterossexuais masculinos a partir dos anos 90, a disseminação espacial da epidemia de AIDS entre as mulheres é igualmente expressiva (Figura 5). Das 26 RAs, entre os anos de 1988 e 1990, 73\% apresentavam taxas médias de incidência para o sexo feminino menores do que 7,0 por 100.000 mulheres. Entre 1991 e 1993, esse percentual passa a ser de $27 \%$, e entre 1994 e 1996, somente a Barra da Tijuca está nesta condição.

Os resultados do modelo estatístico apontam para conclusão semelhante, indicando efeito significativo de difusão espacial, nos dois momentos estudados (Tabela 4). Entretanto, chama a atenção que do segundo para o terceiro período, a expansão geográfica privilegia a direção de 135 graus. Como pode ser observado no mapa que corresponde aos anos de 1994 a 1996, de fato, pode-se perceber um conglomerado de taxas elevadas que se expande pela chamada região da Leopoldina, na direção noroeste.

Os achados da análise espacial dos casos pediátricos por transmissão vertical, mostram uma distribuição espacial não aleatória no período 1985-1990 (Tabela 5), observando-se um coeficiente de autocorrelação espacial, estatisticamente significativo no nível de 0,001, assim 


\section{Figura 3}

Distribuição espacial das taxas de incidência de AIDS (por 100.000 habitantes) entre os homossexuais masculinos por período de tempo. Município do Rio de Janeiro, 1988-1996.

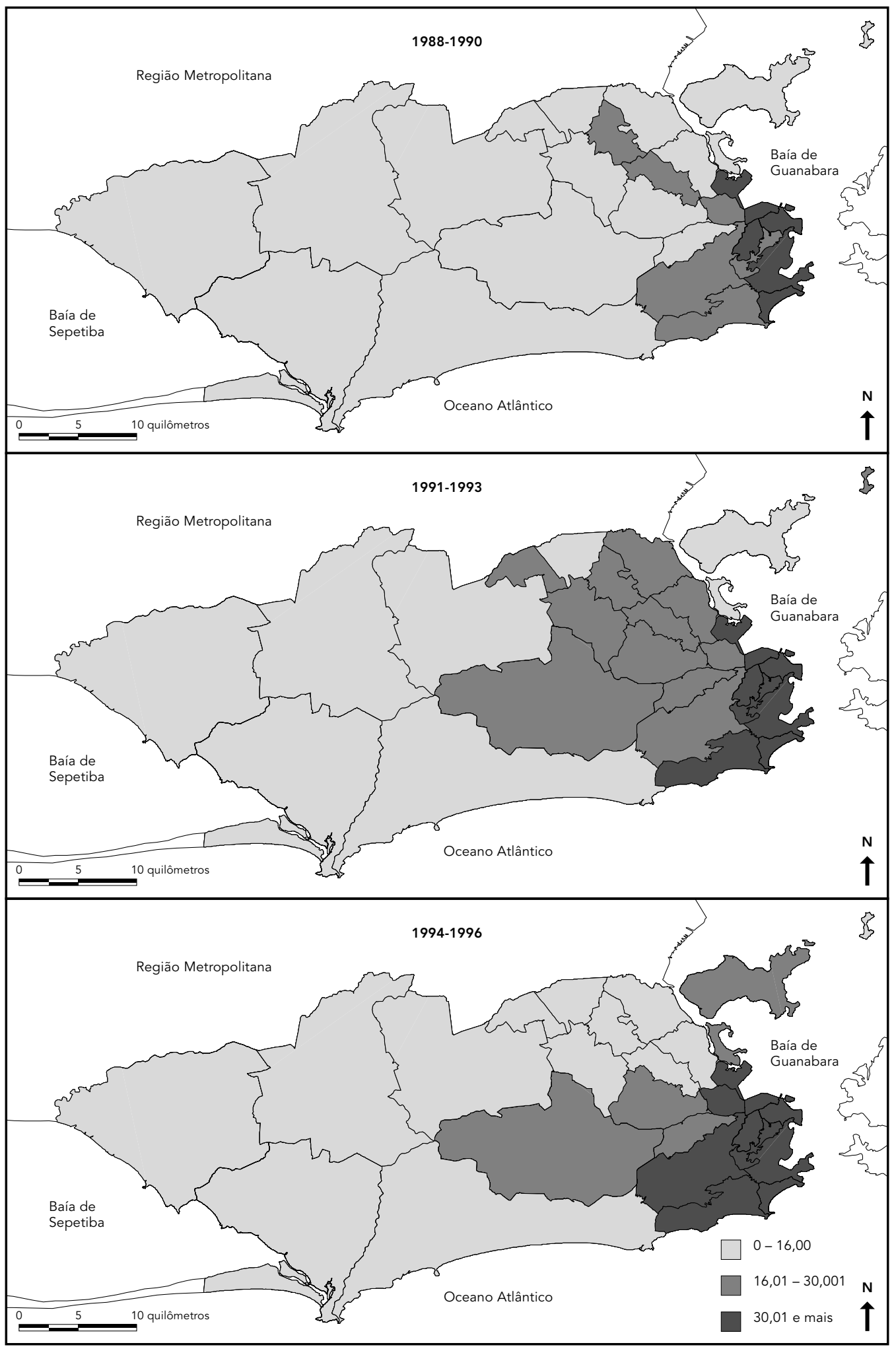


Resultados do procedimento stepwise para os homossexuais masculinos.

\begin{tabular}{|c|c|c|c|c|}
\hline \multirow[t]{2}{*}{ Variáveis } & \multicolumn{2}{|c|}{ Período 1 para o Período 2} & \multicolumn{2}{|c|}{ Período 2 para o Período 3} \\
\hline & Parâmetro & p-valor & Parâmetro & p-valor \\
\hline Constante & 0,993 & 0,016 & 0,437 & 0,256 \\
\hline Vizinho temporal & 0,976 & 0,000 & 0,849 & 0,000 \\
\hline Vizinho espaço-temporal & - & NS & - & NS \\
\hline Constante & 0,025 & 0,961 & 0,867 & 0,053 \\
\hline Vizinho temporal & 1,131 & 0,000 & 0,788 & 0,000 \\
\hline Vizinho espaço-temporal na direção de $45^{\circ}$ & - & NS & - & NS \\
\hline Constante & 1,651 & 0,003 & $-0,024$ & 0,965 \\
\hline Vizinho temporal & 0,792 & 0,000 & 0,939 & 0,000 \\
\hline Vizinho espaço-temporal na direção de $90 \circ$ & - & NS & - & NS \\
\hline Constante & 0,615 & 0,143 & 0,340 & 0,483 \\
\hline Vizinho temporal & 1,049 & 0,000 & 0,859 & 0,000 \\
\hline Vizinho espaço-temporal na direção de $135^{\circ}$ & - & NS & - & NS \\
\hline Constante & 0,756 & 0,111 & 0,131 & 0,810 \\
\hline Vizinho temporal & 0,757 & 0,000 & 0,911 & 0,000 \\
\hline Vizinho espaço-temporal na direção de $180^{\circ}$ & 0,315 & 0,031 & - & NS \\
\hline
\end{tabular}

NS = não significante.

como uma associação significativa $(\mathrm{p}=0,019)$ na direção horizontal ( $\pi \mathrm{rd}$ ). A área que concentra taxas elevadas tem um formato poligonal, situando-se no setor sudeste da cidade, que se constitui da Portuária, Vila Isabel, Santa Teresa, Centro, Botafogo, São Cristóvão, Rio Comprido e Tijuca (Figura 6). Essa região é exatamente a área que representa a fase inicial da epidemia no município e a que concentra os primeiros casos de AIDS entre as mulheres.

Por outro lado, os resultados para o segundo período (anos de nascimento entre $1991 \mathrm{e}$ 1996) demonstram a grande ampliação do número de crianças infectadas pelo HIV por transmissão vertical, sendo que a autocorrelação espacial passa a ser estatisticamente não significativa. No mapa correspondente a esse período (Figura 6) percebe-se que não há mais um conglomerado poligonal de taxas elevadas, mas uma grande expansão do aglomerado da Zona Portuária no período anterior, incorporando diversas outras RAs, tanto ao noroeste como as de Méier, Madureira, Irajá, Bangu e Pavuna, quanto ao sul, como as de Copacabana e Lagoa. Chamam a atenção ainda as taxas elevadas no outro extremo da cidade, nas RAs de Santa Cruz e Guaratiba, áreas reconhecidas como de baixo padrão sócio-econômico.

Os resultados obtidos na análise de correlações, apresentados na Tabela 6 confirmam a associação da infecção por HIV entre as crianças com o nível de pobreza da RA, no período de 1991-1996. Os coeficientes de correlação são significativos para ambos os indicadores considerados, "proporção de chefes de domicílio que têm renda mensal menor que um salário mínimo" e "proporção de mulheres de 1549 anos analfabetas".

\section{Discussão}

São apresentados, no presente trabalho, os resultados da aplicação de um modelo espaçotemporal às taxas de incidência de AIDS no Município do Rio de Janeiro, segundo a RA de residência. Ainda que sabidamente heterogêneas na sua composição interna do ponto de vista sócio-demográfico, os contrastes entre as RAs são evidentes, e têm permitido, em trabalhos anteriores (Szwarcwald et al., 1999a, 1999b, 2000), estudar as relações entre desigualdade social e diferentes agravos à saúde no Município do Rio de Janeiro.

A análise buscou caracterizar os padrões de difusão da epidemia segundo as distintas categorias de exposição. Até onde é do nosso conhecimento, apresentamos aqui, pela primeira vez, não só dados referentes às tendências da disseminação da AIDS entre adultos, mas igual- 


\section{Figura 4}

Distribuição espacial das taxas de incidência de AIDS (por 100.000 habitantes) entre os heterossexuais por período de tempo. Município do Rio de Janeiro, 1988-1996.

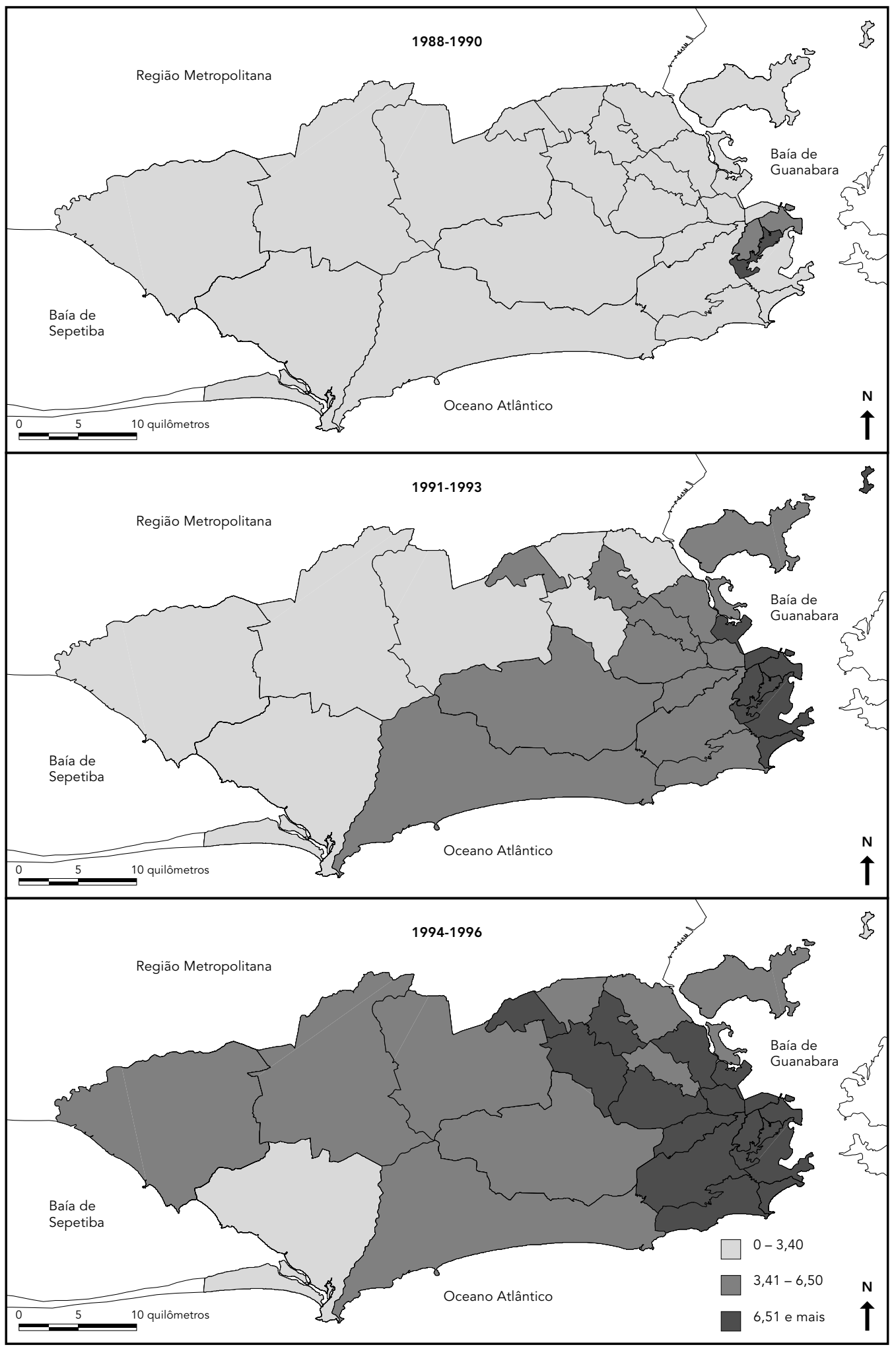


Resultados do procedimento stepwise para os heterossexuais.

\begin{tabular}{|c|c|c|c|c|}
\hline \multirow[t]{2}{*}{ Variáveis } & \multicolumn{2}{|c|}{ Período 1 para o Período 2} & \multicolumn{2}{|c|}{ Período 2 para o Período 3} \\
\hline & Parâmetro & p-valor & Parâmetro & p-valor \\
\hline Constante & 0,129 & 0,744 & 0,665 & 0,060 \\
\hline Vizinho temporal & 0,487 & 0,025 & 0,928 & 0,000 \\
\hline Vizinho espaço-temporal & 1,119 & 0,002 & - & NS \\
\hline Constante & 1,207 & 0,037 & 0,700 & 0,137 \\
\hline Vizinho temporal & 0,860 & 0,022 & 0,939 & 0,000 \\
\hline Vizinho espaço-temporal na direção de $45^{\circ}$ & - & NS & - & NS \\
\hline Constante & 0,783 & 0,026 & 0,521 & 0,128 \\
\hline Vizinho temporal & 0,448 & 0,035 & 0,496 & 0,009 \\
\hline Vizinho espaço-temporal na direção de $90 \circ$ & 0,638 & 0,009 & 0,433 & 0,008 \\
\hline Constante & 0,825 & 0,049 & 0,326 & 0,365 \\
\hline Vizinho temporal & 1,073 & 0,002 & 1,132 & 0,000 \\
\hline Vizinho espaço-temporal na direção de $135^{\circ}$ & - & NS & - & NS \\
\hline Constante & 1,419 & 0,000 & 0,896 & 0,121 \\
\hline Vizinho temporal & 0,531 & 0,001 & 0,813 & 0,005 \\
\hline Vizinho espaço-temporal na direção de $180^{\circ}$ & - & NS & - & NS \\
\hline
\end{tabular}

NS = não significante.

mente uma análise da distribuição espacial dos casos pediátricos de AIDS por transmissão vertical.

Como evidenciado nos sucessivos boletins epidemiológicos editados pela Coordenação Nacional de DST/AIDS do Ministério da Saúde (MS, 1999) e em trabalhos anteriores (Szwarcwald et al., 1998), a epidemia de AIDS se inicia na década de 80 nas grandes metrópoles, afetando de forma especialmente vigorosa aqueles que receberam sangue e hemoderivados e os homossexuais masculinos.

A aplicação do modelo de difusão espacial para os casos entre homossexuais masculinos registrou um processo de expansão geográfica da epidemia pouco relevante, com crescimento in situ nitidamente predominante. O período inicial (1988-1990) é marcado por um conglomerado de taxas elevadas, que tem origem no litoral (área portuária e Copacabana) e se expande na direção leste-oeste. Já em meados da década, observa-se um arrefecimento da disseminação espacial da epidemia nesta população, provavelmente, em parte, devido à saturação dos suscetíveis, em um dado período e espaço geográfico, em parte devido à mudança de comportamento da população de homossexuais masculinos em relação às medidas preventivas.

O peso relativo da epidemia entre os homossexuais masculinos influencia de forma impor- tante o padrão de difusão da epidemia como um todo, sobretudo no início dos anos 90, que, igualmente, apresenta uma concentração de taxas elevadas em um conglomerado geográfico situado ao redor da Zona Portuária, e efeito de expansão espacial que ocorre apenas para a direção oeste-leste ( $\pi$ rd). Entretanto, na fase posterior, diferentemente do processo de retração encontrado entre os homossexuais masculinos, o padrão de disseminação da epidemia geral passa a refletir, ainda que parcialmente, a expansão dos casos por transmissão heterossexual, que passam a ter magnitude expressiva a partir dos anos 90.

Embora os casos decorrentes da transmissão heterossexual tenham sido relativamente poucos no momento inicial da epidemia, experimentam, posteriormente, um incremento contínuo e bastante relevante, especialmente na década de 90, fazendo-se acompanhar de uma profunda alteração da razão de sexo - com um aumento progressivo do número de casos de AIDS entre as mulheres - e um incremento, igualmente progressivo, dos casos pediátricos devido à transmissão vertical do HIV (MS, 1999).

A presente análise evidenciou uma expansão significativa dos casos registrados entre "heterossexuais", no conjunto de direções (difusão onidirecional) do primeiro para o segundo período, e um processo seletivo de difusão 


\section{Figura 5}

Distribuição espacial das taxas de incidência de AIDS (por 100.000 habitantes) entre as mulheres adultas por período de tempo. Município do Rio de Janeiro, 1988-1996.

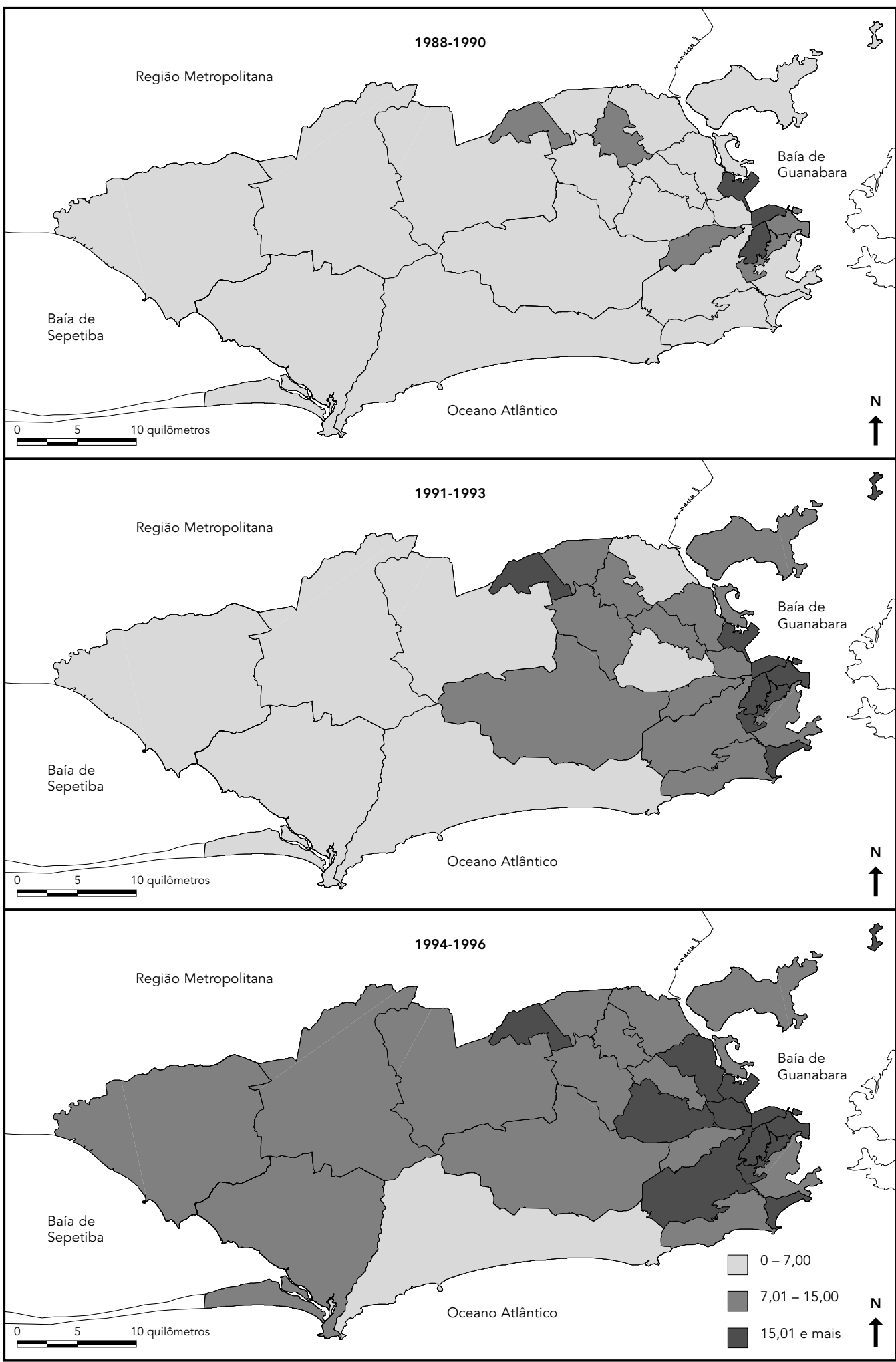


Resultados do procedimento stepwise para as mulheres em função dos heterossexuais masculinos.

\begin{tabular}{|c|c|c|c|c|}
\hline \multirow[t]{2}{*}{ Variáveis } & \multicolumn{2}{|c|}{ Período 1 para o Período 2} & \multicolumn{2}{|c|}{ Período 2 para o Período 3} \\
\hline & Parâmetro & p-valor & Parâmetro & p-valor \\
\hline Constante & 0,561 & 0,368 & 0,752 & 0,278 \\
\hline Vizinho temporal & 0,898 & 0,006 & 0,630 & 0,019 \\
\hline Vizinho espaço-temporal & 1,027 & 0,032 & 0,681 & 0,076 \\
\hline Constante & 1,124 & 0,116 & 1,620 & 0,045 \\
\hline Vizinho temporal & 1,561 & 0,001 & 0,987 & 0,002 \\
\hline Vizinho espaço-temporal na direção de $45^{\circ}$ & - & NS & - & NS \\
\hline Constante & 0,966 & 0,108 & 1,335 & 0,106 \\
\hline Vizinho temporal & 0,681 & 0,046 & 1,100 & 0,003 \\
\hline Vizinho espaço-temporal na direção de $90 \circ$ & 0,938 & 0,012 & - & NS \\
\hline Constante & 1,310 & 0,032 & 0,769 & 0,282 \\
\hline Vizinho temporal & 1,367 & 0,002 & 0,659 & 0,011 \\
\hline Vizinho espaço-temporal na direção de $135^{\circ}$ & - & NS & 0,712 & 0,033 \\
\hline Constante & 2,087 & 0,000 & 2,396 & 0,000 \\
\hline Vizinho temporal & 0,666 & 0,007 & 0,569 & 0,011 \\
\hline Vizinho espaço-temporal na direção de $180 \circ$ & - & NS & - & NS \\
\hline
\end{tabular}

NS = não significante.

Tabela 5

Coeficientes de autocorrelação espacial (I) para as taxas de incidência de AIDS decorrentes da transmissão vertical por período de nascimento da criança.

\begin{tabular}{|c|c|c|c|c|}
\hline \multirow[t]{2}{*}{ Relação de vizinhança } & \multicolumn{2}{|c|}{$1985-1990$} & \multicolumn{2}{|c|}{ 1991-1996 } \\
\hline & 1 & p-valor & 1 & p-valor \\
\hline Em todas as direções & 0,640 & 0,001 & 0,310 & 0,131 \\
\hline Na direção de $45^{\circ}$ & 0,347 & 0,158 & 0,446 & 0,064 \\
\hline Na direção de $90^{\circ}$ & 0,460 & 0,073 & $-0,188$ & 0,486 \\
\hline Na direção de $135^{\circ}$ & 0,285 & 0,237 & 0,270 & 0,263 \\
\hline Na direção de $180 \circ$ & 0,518 & 0,019 & $-0,449$ & 0,047 \\
\hline
\end{tabular}

na direção norte, tanto do primeiro para o segundo como do segundo para o terceiro período, dirigindo-se aos municípios do Cinturão Metropolitano do estado. Adicionalmente, considerando-se a correlação entre os casos de AIDS registrados entre homens da categoria de exposição heterossexual em um dado período de tempo (que figura aqui como um proxi do pool de infectantes em relação às mulheres infectadas por via sexual) e entre as mulheres em um momento subseqüente, observa-se padrão semelhante ao encontrado para a totalidade dos casos heterossexuais.
Entretanto, chama a atenção que, entre as mulheres, um segundo ângulo (1350) de expansão se mostrou relevante no que diz respeito ao processo de difusão do segundo para o terceiro período. A distribuição espacial das taxas de incidência de AIDS para o sexo feminino, nos meados da década de 90 (1994-96), é caracterizada por um nítido conglomerado em torno de um eixo na direção noroeste, que tem origem na Zona Portuária e acompanha a linha férrea da Leopoldina e a Avenida Brasil. Compreendendo as RAs com a maior concentração de população favelada do município (Szwarcwald 


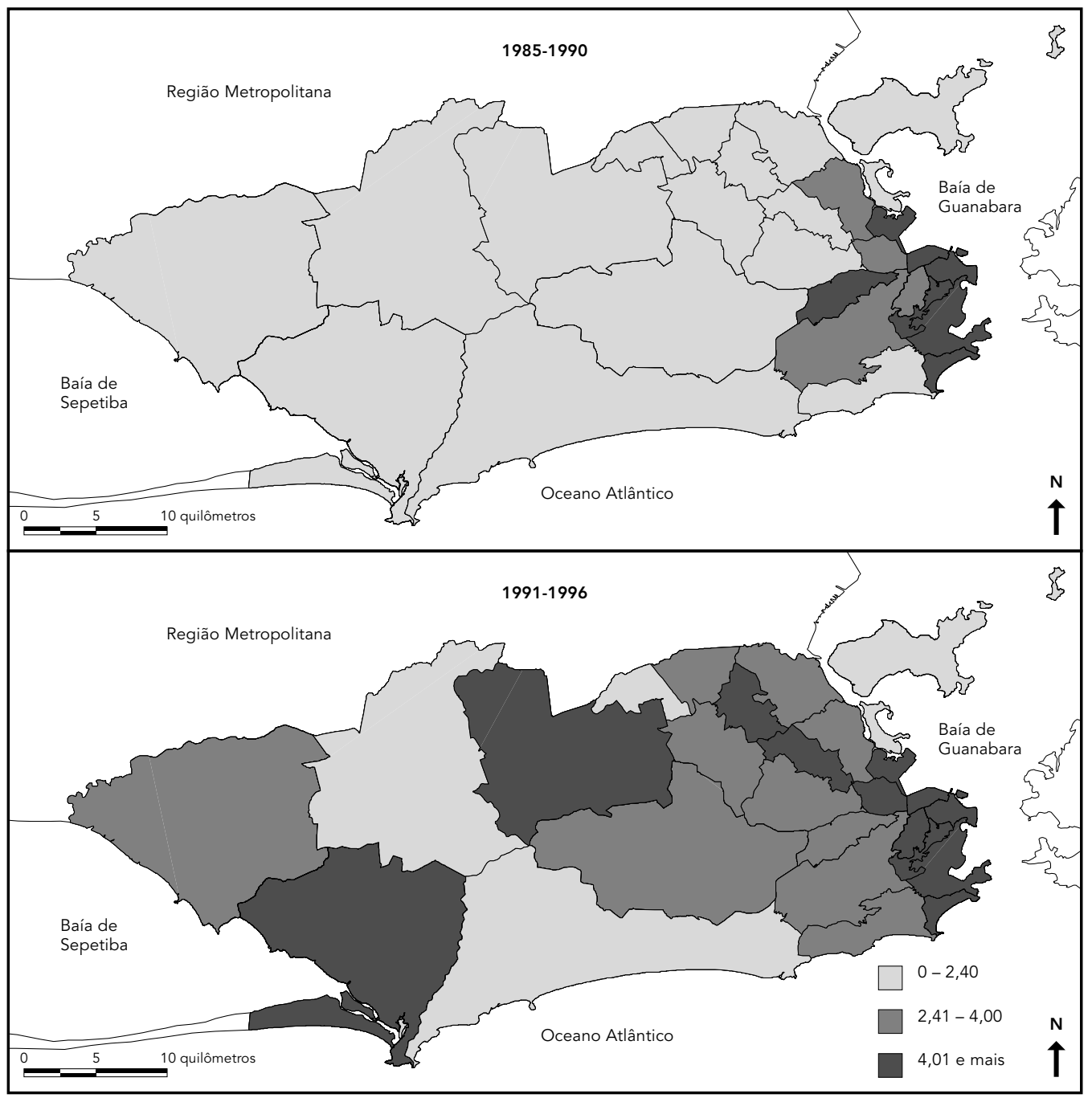

et al., 2000), que se situam em torno desse eixo, o padrão espacial encontrado mostra sinais claros do processo de "pauperização" da epidemia entre as mulheres.

Conforme discutido por Farmer et al. (1996), as mulheres e, particularmente, as residentes nas comunidades mais pobres, desprovidas de uma real autonomia social, política, econômica e cultural, inúmeras vezes se deparam com a falta de acesso a informações culturalmente apropriadas e recursos para implementar de forma consistente ações preventivas e, mais do que isso, se vêem às voltas com valores e iniciativas que se opõem frontalmente a estas ações preventivas, sob a forma de preconceitos, cons- trangimentos, quando não de ações coercitivas e violentas.

A análise dos casos de AIDS registrados entre as crianças que se infectaram devido à transmissão vertical, examinando-se os dados por ano de nascimento da criança, revela mudanças importantes no padrão espacial das taxas de incidência de AIDS perinatal do período de 1985-1990 para os anos mais recentes, entre 1991 e 1996. De forma consistente aos resultados obtidos por meio da análise desenvolvida para os casos adultos, a distribuição espacial inicial dos casos por transmissão vertical é marcada por um conglomerado poligonal em torno da Zona Portuária. No período seguinte, 
Coeficientes de correlação $(r)$ entre as taxas de incidência de AIDS decorrentes da transmissão

vertical com indicadores sócio-econômicos por período de nascimento da criança.

\begin{tabular}{lcccc}
\hline Indicadores & \multicolumn{3}{c}{ Taxas de AIDS decorrentes da transmissão vertical } \\
& 1985-1990 & p-valor & 1991-1996 & p-valor \\
\hline $\begin{array}{l}\text { Proporção de chefes com renda } \\
\text { mensal menor que 1 salário mínimo }\end{array}$ & $-0,027$ & 0,894 & 0,509 & 0,007 \\
$\begin{array}{l}\text { Proporção de mulheres de 15 a } 49 \\
\text { anos analfabetas }\end{array}$ & 0,110 & 0,585 & 0,459 & 0,016 \\
\hline
\end{tabular}

além da nítida expansão dos casos por toda a cidade, a correlação ecológica das taxas de incidência com o índice de concentração de pobreza passa a ser estatisticamente significativa, corroborando os achados da análise espaçotemporal dos casos do sexo feminino.

Tendo em vista a defasagem temporal relevante entre infecção pelo HIV e registro de caso de AIDS (Porter et al., 1999), as análises que têm como base de informações os casos de AIDS notificados em crianças que se infectaram por via vertical podem vir a se constituir em um componente importante para uma avaliação mais dinâmica da distribuição espacial da infecção por HIV entre as mulheres, principalmente as jovens. Embora o estudo tenha considerado como unidade geográfica de análise a RA de residência da mãe no momento de notificação, e não no momento de nascimento da criança, a análise espacial demonstrou coerência dos resultados em ambos os períodos de tempo, como já apontado anteriormente.

Nesse sentido, o cruzamento dos dados do Sistema de Informações de Agravos de Notificação (SINAN) dos casos pediátricos com o SINASC nos anos após 1993 (ano de implantação do SINASC no município) pode vir a contribuir expressivamente para a caracterização do perfil de mães infectadas pelo HIV, e, inclusive, corrigir a limitação de desconhecimento da área de residência da mãe no momento do nascimento da criança, informação não disponível no SINAN mas presente no SINASC.

Os dados aqui apresentados deixam clara a necessidade de, no intuito de reduzir a expansão da epidemia de HIV/AIDS, combinar medidas preventivas de curto e longo prazo, dirigidas a segmentos populacionais específicos e ao conjunto da população, enfocando determinantes tanto conjunturais como estruturais da disseminação da epidemia em nosso contexto.

No primeiro grupo de iniciativas mencionaríamos as estratégias de educação para a saúde; a distribuição e o marketing social dos preservativos (masculinos, e, sempre que possível, também femininos); e o diagnóstico, aconselhamento e tratamento das infecções sexualmente transmissíveis.

Não pode-se deixar de enfatizar aqui (uma vez constatada uma expansão vigorosa da epidemia em mulheres e sua prole) a otimização dos serviços pré-natais, aumentando a aderência da população (especialmente pobre, que é, freqüentemente, acompanhada de forma pouco sistemática) com implementação plena das “melhores práticas” no âmbito da prevenção da transmissão vertical do HIV, que têm determinado reduções muito substanciais do número de novas infecções por esta via de transmissão (Mofenson \& Fowler, 1999).

Os achados falam igualmente a favor de programas de promoção da saúde e promoção social que incorporem, além da dimensão exclusivamente individual, a atuação em nível das comunidades, procurando contribuir para a mudança comportamental e a de atitudes e práticas que se contrapõem às ações preventivas (como o machismo, a homofobia ou o fatalismo frente à epidemia).

No que se refere à metodologia utilizada, mostrou-se, claramente, na presente análise, que a interpretação de mapas à luz das evidências estatísticas pode fornecer contribuições importantes à compreensão dos processos que delineiam os padrões espaciais de doenças. Especificamente, no tocante à AIDS, os resultados sugerem que o entendimento da dinâmica da epidemia na sua dimensão espaço-temporal pode subsidiar de forma relevante as ações preventivas, devendo se constituir em um objeto de investigação permanente, sobretudo nas metrópoles brasileiras, caracterizadas por enormes disparidades sociais e culturais.

Entretanto, cabe apontar as várias restrições encontradas na elaboração deste trabalho, im- 
postas, principalmente, por se tratar de um estudo que utilizou dados secundários. Entre elas, destaca-se o grande percentual de casos com categoria de exposição ignorada, crescente com o tempo, superior a 30\%, no período de 1994-96.

Vale dizer que a falta de qualidade dos dados de notificação pode ter acarretado apreciações incorretas dos dados analisados. Como houve um aumento dos casos com categoria de exposição ignorada a partir do início dos anos 90, período que coincide com a expansão dos casos por transmissão heterossexual, é possível que a difusão espacial nesta população, do segundo para o terceiro período, tenha sido bem mais vigorosa do que a descrita na presente análise.

Neste contexto, é fundamental enfatizar a necessidade premente de uma intensificação da vigilância dos dados de notificação no Brasil, para que as análises desenvolvidas a partir dos dados do SINAN, como as aqui apresentadas, não deixem margens tão largas de incertezas quanto aos resultados encontrados, e possam subsidiar, com maior credibilidade, as ações e os programas de saúde.

\section{Referências}

ANDERSON, R. M., 1996. The spread of HIV and sexual mixing patterns. In: AIDS in the World II (J. M. Mann \& D. Tarantola, ed.), pp. 71-86, New York: Oxford University Press.

BARBOSA, M. T. S. \& STRUCHINER, C. J., 1997. Estimativas do número de casos de AIDS: Comparação de métodos que corrigem o atraso da notificação. In: A Epidemia de AIDS no Brasil: Situação e Tendências (P. N. Chequer \& M. G. Medeiros, org.), pp. 15-26, Brasília: Coordenação Nacional de DST e AIDS, Secretaria de Projetos Especiais de Saúde, Ministério da Saúde.

BARCELLOS, C. \& BASTOS, F. I., 1996. Redes sociais e difusão da AIDS no Brasil. Boletín de la Oficina Sanitaria Panamericana, 121:11-24.

BASTOS, F. I. \& BARCELLOS, C., 1995. Geografia social da AIDS no Brasil. Revista de Saúde Pública, 29:52-62.

BESAG, J. E. \& NEWELL, J., 1991. The detection of clusters in rare diseases. Journal of the Royal Statistical Society, Series A, 154:143-155.

BESAG, J. E., 1977. Errors in variable estimation for Gaussian lattice schemes. Journal of the Royal Statistical Society, Series B, 39:73-78.

BROOKMEYER, R., 1996. AIDS, epidemics, and statistics. Biometrics, 52:781-796.

CLIFF, A. D. \& ORD, J. K., 1973. Spatial Autocorrelation. London: Pion.

CLIFF, A. D. \& ORD, J. K., 1981. Spatial Processes. Models \& Applications. London: Pion.

CRESSIE, N., 1993. Statistics for Spatial Data. New York: John Wiley \& Sons.

FARMER, P.; CONNORS, M. \& SIMMONS, J., 1996. Women, Poverty, and AIDS: Sex, Drugs and Structural Violence. Monroe: Common Courage Press.
GRANGEIRO, A., 1994. O perfil sócio-econômico da AIDS no Brasil. In: A AIDS no Brasil (R. Parker, C. Bastos, J. Galvão \& J. S. Pedrosa, org.), pp. 91-128, Rio de Janeiro: Associação Brasileira Interdisciplinar de AIDS/Universidade Estadual do Rio de Janeiro/Relume-Dumará.

GREENLAND, S.; LIEB, L.; SIMON, P.; FORD, W. \& KERNDT, P., 1996. Evidence for recent growth of the HIV epidemic among African-American men and younger male cohorts in Los Angeles County. Journal of Acquired Immune Deficiency Syndromes and Human Retrovirology, 11:401-409.

HAGGE, T. P., 1976. Hybridizing alternative models of an epidemic diffusion process. Economic Geography, 52:136-146.

HALLORAN, M. E. \& STRUCHINER, C. J., 1991. Study designs for dependent happenings. Epidemiology, 2:331-338.

HILLS, M. \& ALEXANDER, F., 1989. Statistical methods used in assessing the risk of disease near a source of possible environmental pollution: A review. Journal of the Royal Statistical Society, Series A, 152:307-325.

IBGE (Fundação Instituto Brasileiro de Geografia e Estatística), 1994. Censo Demográfico, Brasil 1991. Rio de Janeiro: IBGE.

IBGE (Fundação Instituto Brasileiro de Geografia e Estatística), 1998. Contagem da População, 1996. v. I e II. Rio de Janeiro: IBGE.

JACQUEZ, G. M., 1996. Disease cluster statistics for imprecise space-time locations. Statistics in Medicine, 15:873-885.

KHEIFETS, L. I., 1993. Cluster analysis: A perspective. Statistics in Medicine, 12:1755-1756.

KLOVDAHL, A. S., 1985. Social networks and the 
spread of infectious diseases: The AIDS example. Social Science and Medicine, 21:1203-1216.

KNOX, E. G., 1964. The detection of space-time interactions. Applied Statistics, 13:25-29.

KULLDORFF, M. \& NAGARWALLA, N., 1995. Spatial disease clusters: Detection and inference. Statistics in Medicine, 14:799-810.

LAM, N. S. N.; FAN, M. \& LIU, K. B., 1996. Spatial-temporal spread of the AIDS epidemic, 1982-1990: A correlogram analysis of four regions of the United States. Geographical Analysis, 28:93-107.

LAWSON, A. B. \& VIEL, J. F., 1995. Tests for directional space-time interaction in epidemiological data. Statistics in Medicine, 14:2383-2391.

LÖYTÖNEN, M., 1994. Growth models and the HIV epidemic in Finland. Social Science and Medicine, 38:179-185.

MANN, J. M.; TARANTOLA, D. \& NETTER, T. W., 1992. AIDS in the World. Cambridge: Harvard University Press.

MANTEL, N., 1967. The detection of disease clustering and a generalized regression approach. Cancer Research, 27:209-220.

MAPINFO CORPORATION, 1994. MapInfo Reference. New York: MapInfo Corporation.

MARSHALL, R. J., 1991. A review of methods for the statistical analysis of spatial patterns of disease. Journal of the Royal Statistical Society, Series A, 154:421-441.

MAYER, J. D., 1983. The role of spatial analysis and geographic data in the detection of disease causation. Social Science and Medicine, 17:12131221.

MS (Ministério da Saúde), 1999. Boletim Epidemiológico-AIDS, 12(4). Brasília: Ministério da Saúde.

MOFENSON, L. M. \& FOWLER, M. G., 1999. Interruption of materno-fetal transmission. AIDS, 13:S205S214.

MORAN, P. A. P., 1950. Notes on continuous stochastic phenomena. Biometrika, 37:17-23.

MORRIS, M., 1991. A log-linear modeling framework for selective mixing. Mathematical Biosciences, 107:349-377.

ODEN, N., 1995. Adjusting Moran's I for population density. Statistics in Medicine, 14:17-26.

PORTER, K.; JOHNSON, A. M.; PHILLIPS, A. N. \& DARBYSHIRE, J. H., 1999. The practical significance of potential biases in estimates of the AIDS incubation period distribution in the UK register of HIV seroconverters. AIDS, 13:1943-1951.
SPSS INCORPORATION, 1995. Base System Syntax Reference Guide. Release 7.0. Chicago: SPSS Inc.

SZWARCWALD, C. L. \& BASTOS, F. I., 1998. Spatiotemporal model: An application to the AIDS epidemic in São Paulo, Brazil. In: Geomed '97 (L. Gierl, A. D. Cliff, A.-J. Valleron, P. Farrington \& M. Bull, ed.), pp. 43-53, Stuttgart/Leipzig: B. G. Teubner.

SZWARCWALD, C. L.; BASTOS, F. I.; ANDRADE, C. L. T. \& CASTILHO, E. A., 1997. AIDS: O mapa ecológico do Brasil, 1982-1994. In: A Epidemia de AIDS no Brasil: Situação e Tendências (P. N. Chequer \& M. G. Medeiros, org.), pp. 27-44, Brasília: Coordenação Nacional de DST e AIDS, Secretaria de Projetos Especiais de Saúde, Ministério da Saúde.

SZWARCWALD, C. L.; BASTOS, F. I.; BARCELLOS, C.; PINA, M. F. \& ESTEVES, M. A., 2000. Health conditions and residential concentration of poverty: A study in Rio de Janeiro, Brazil. Journal of Epidemiology and Community Health, 54:530-536.

SZWARCWALD, C. L.; BASTOS, F. I. \& CASTILHO, E. A., 1998. The dynamics of the AIDS epidemic in Brazil: A space-time analysis in the period 19871995. Brazilian Journal of Infectious Diseases, 2:175-186.

SZWARCWALD, C. L.; BASTOS, F. I.; VIACAVA, F. \& ANDRADE, C. L. T., 1999a. Income inequality and homicide rates: A study in Rio de Janeiro, Brazil. American Journal of Public Health, 89:845-850.

SZWARCWALD, C. L.; BASTOS, F. I.; ESTEVES, M. A. P.; ANDRADE, C. L. T.; PAEZ, M. S.; MEDICI, E. V. \& DERRICO, M., 1999b. Desigualdade de renda e situação de saúde: O caso do Rio de Janeiro. $\mathrm{Ca}$ dernos de Saúde Pública, 15:15-28.

TANGO, T., 1995. A class of tests for detecting 'general' and 'focused' clustering of rare diseases. Statistics in Medicine, 14:2323-2334.

WALDHÖR, T., 1996. The spatial autocorrelation coeficient Moran's I under heteroscedasticity. Statistics in Medicine, 15:887-892.

WALLACE, R. \& WALLACE, D., 1995. US apartheid and the spread of AIDS to the suburbs. A multi-city analysis of the political-economy of spatial epidemic threshold. Social Science \& Medicine, 41: 333-345.

ZIERLER, S. \& KRIEGER, N., 1997. Reframing women's risk: Social inequalities and HIV infection. Annual Review of Public Health, 18:401-436. 